\begin{tabular}{|c|c|}
\hline $\begin{array}{l}\text { 研究助成 } \\
\text { 成果報告 }\end{array}$ & $\begin{array}{c}\text { ホソカワ粉体工学振興財団年報 } \\
\text { Hosokawa Powder Technology Foundation ANNUAL REPORT }\end{array}$ \\
\hline
\end{tabular}

15120

\title{
微小粒子添加法による排出流動性向上効果の機構解析 \\ An Investigation of Mechanisms of Improving Discharge Particle Flowability in a Smaller Particle Admixing System
}

\author{
研究代表者 Research leader：吉田 幹生 Mikio YOSHIDA \\ 同志社大学理工学部 准教授 \\ Faculty of Science and Engineering, Doshisha University, Associate Professor \\ E-mail: miyoshid@mail.doshisha.ac.jp
}

\section{抄 録}

粒子流動性を向上させる手法の 1 つに微小粒子添加法がある。しかし, 流動性向上メカニズムは十 分に明らかになっていない. 本研究では, そのメカニズムを検討するため, 振動排出時の流動性に 着目し, 添加粒子による主粒子表面粗さが流動性向上効果に及ぼす影響を検討した。主粒子には 41.4, $60.8 \mu \mathrm{m}$ ， 添加粒子には $8,104 \mathrm{~nm}$ の試料を用いた．主粒子と添加粒子を所定の割合で混合し た試料の排出流量を測定し, 主粒子のみの場合と比較した。また各混合試料の被覆状態を異なる角 度からSEMにより撮影し, 画像解析ソフトにより 3 次元の粗さ情報を取得した。検討の結果, 振 動排出時の流動性向上効果は, 圧密充填時の場合とは異なる傾向が確かめられた。また, 振動排出 流動性が最大となる被覆状態を検討したところ, RMS 值が約 $0.1 \mu \mathrm{m}$, 凹凸の周期が約 $3.2 \mu \mathrm{m}$ であ ることが示された.

\begin{abstract}
Particle flowability can be improved by admixing particles smaller than the main particles. However, the mechanism by which this technique improves flowability has not yet fully understood. In the present study, we focused on vibrating discharge particle flowability as one of the type of flowabilities, and we investigated the effects of the main particle roughness created by adhesions of admixed particles on improving the flowability. The main and admixed particles were 41.4, $60.8 \mu \mathrm{m}$ and $8,104 \mathrm{~nm}$ in diameters, respectively. The main and admixed particles were mixed for various mass ratios, and discharge particle flow rates for the mixed particles were measured. We captured SEM images from 2 different directions and obtained 3-dimensional surface roughnesses by an image analysis software. We calculated RMS roughness values and conducted Fourier Transform analysis for the obtained 3-dimensional surface roughness. As a result, the improving trends of vibrating discharge particle flowability differed from those of compression particle flowability. Furthermore, the main particle roughness conditions showing the most improvement were as follows. RMS roughness value were around $0.1 \mu \mathrm{m}$ and roughness wavelength were around $3.2 \mu \mathrm{m}$.
\end{abstract}




\section{研究背景と目的}

粉体は粒子径が小さいほど，大きな比表面積 を持つため, 反応性や溶解性が高くなる。一方 で，粒子の付着性も増加するため, 流動性の悪 化を招き，しばしば製造プロセス中でのトラブ ルを引き起こす。よって, 粒子径が小さな粉 体の流動性を向上させる手法の開発は重要で ある。

粉体の流動性を向上させる手法の1つに微小 粒子添加法 (Zimmermann I. et al., 2004; Jonat S. et al., 2004; Chen Y.H. et al., 2010）がある. 本手 法は, 目的となる粒子（主粒子）に対し, さら に微小な粒子を添加することで主粒子の表面に 粗さなどを形成し，流動性を向上させる手法で ある。しかし，本手法に打ける詳細なメカニズ ムは不明であり，流動性の制御ができるまでに 至っていない，具体的には，流動性が向上する 主な理由として，1）スペーサー効果（添加粒 子が主粒子間に存在することにより主粒子間の 付着力が減少），2）ベアリング効果（添加粒子 が主粒子間の表面で回転することによる主粒子 間の摩擦力の減少）などが提案されているが, 両者だけでは流動性の変化が説明できない部分 も多く, 追加のメカニズムが存在するのではな いかと考えられる.

一般に粉体の流動には, 重力流動, 機械的強 制流動，振動流動，圧密流動（Miwa S., 1981） がある、これまで, 我々の研究グループでは, 圧密流動の操作の 1 つである圧密充填操作に着 目し，できるだけメカニズムを検討しやすいシ ンプルな試料系を用いて追加メカニズムの検討 を行ってきた（Yoshida M. et al., 2013, 2015, 2016, 2017)。 その結果, 添加粒子が主粒子の間 に存在することによって, 力学モデルが剛体棒 連結モデルに変化し, 主粒子運動の自由度の増 加による流動性向上メカニズムを提案してき た。しかし，圧密流動は時間変化に伴い粒子間 距離が狭まる挙動であるのに対して，一般に重 力流動, 振動流動などは粒子間距離が広がる挙 動であることが多いため, 同じメカニズムが成
立するかどうかは不明である。そこで，次のス テップとして，粒子間が広がる挙動の 1 つであ る振動排出流動に着目し, 同様にシンプルな試 料系を用いて，流動性向上の追加メカニズムの 検討を試みる。

その追加メカニズムを検討するには, 添加粒 子の主粒子表面への被覆に基づく 3 次元被覆構 造情報がキーであると考えられる。なぜなら， 本向上効果は, 主粒子同士の接触状態が変化す ることで生じると考えられるためである。しか し，これまでの本方法の多くの報告はその被覆 状態が均一あるいは不均一程度の定性的評価に 留まっている場合が多く, 主粒子表面粗さが流 動性向上効果に及ぼす影響が十分に検討されて いないと考えられる。そこで, 本研究では, 様々 な条件で添加した主粒子表面を 2 箇所の異なる 位置から SEM 画像を撮影することにより，3 次元 SEM 画像を構築し, 主粒子の 3 次元被覆 構造情報を取得した。合わせて，それらの試料 に対して, 振動排出流動実験を行い, 被覆構造 情報から得られた定量的な主粒子表面粗さが振 動排出時の流動性向上効果に及ぼす影響を検討 した.

\section{研 究 方 法}

\section{1. 試料と混合割合}

主粒子はガラスビーズ（粒子径 $41.4,60.8 \mu \mathrm{m}$ (チタンバリウム系, 密度 $\left.4.2 \times 10^{3} \mathrm{~kg} / \mathrm{m}^{3}\right)$ ), 添加粒子にシリカ粒子（粒子径 $8,104 \mathrm{~nm}$, 密 度 $\left.2.2 \times 10^{3} \mathrm{~kg} / \mathrm{m}^{3}\right)$ を用いた。主粒子 $5.0 \mathrm{~g}$ に 添加粒子を質量割合が $0.00-0.40$ mass \% になる ように加え，摚拌による混合操作を行った，混 合は内径 $10.3 \mathrm{~mm}$ の PS 製のチューブに試料を 入れた後, ボルテックスミキサー上に固定し， 所定の混合強度で 10 分間行った。

\section{2. 振動排出実験方法}

Fig. 1 に振動排出装置の概略図を示す。下部 に内径 $0.40 \mathrm{~mm}$, 長さ $37 \mathrm{~mm}$ の排出管が取り 付けられた容器（内径 $8.8 \mathrm{~mm}$ ) に前述の方法 


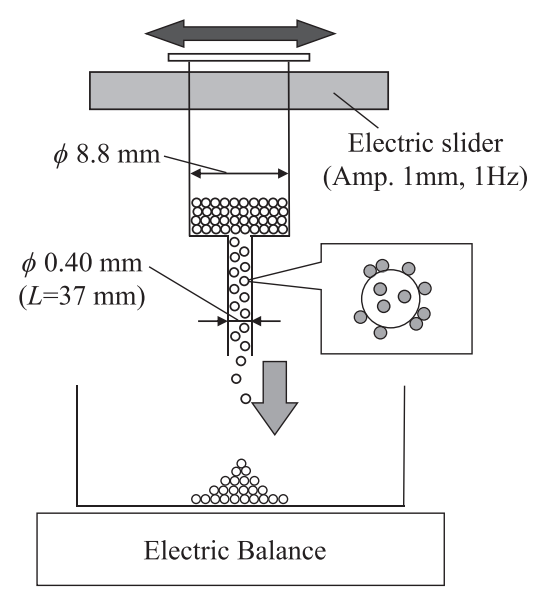

Fig. 1 A schematic view of experimental apparatus.

で調整した試料を投入した。その後, 電動スラ イダーによって水平方向に振幅 $1.0 \mathrm{~mm}$, 周波 数 $1.0 \mathrm{~Hz}$ で振動させ, 試料を排出管から振動 排出させた。その際の排出量を排出管下部に 配置した天秤で計測し，その経時変化から排 出流量 $Q_{\mathrm{d}}$ を算出した。実験は各試料につき 3 回ずつ行った。なお， $60.8 \mu \mathrm{m}$ と $41.4 \mu \mathrm{m}$ の 主粒子のみ（未添加）の場合の $Q_{\mathrm{d}}$ はそれぞれ $3.2 \pm 0.7 \mathrm{mg} / \mathrm{s}, \quad 6.2 \pm 0.8 \mathrm{mg} / \mathrm{s}$ であった。

\section{3. 表面粗さ解析方法}

試料の被覆状態は走査型電子顕微鏡（SEM, KEYENCE VE-9800）を用いて観察した。また, 被覆状態を定量的に評価するため, 試料を 5.0 degree 異なる角度から撮影し, 装置付属のソフ
トウエアにより 3 次元被覆構造情報を構築し た．Fig. 2 にその一例を示す，各添加割合にお いて 50 箇所の高さプロファイルをランダムに 取得し, 次式により二乗平均平方根粗さ (Root Mean Square: RMS）を算出し, その平均值を求 めた。なお，この際，測定箇所の主粒子の曲率 を考慮してベースラインを補正した。

$$
\mathrm{RMS}=\sqrt{\frac{1}{l} \int_{0}^{l} f(x)^{2} \mathrm{~d} x}
$$

ここで, $x$ は各位置, $f(x)$ はベースラインを 基準とした高さ情報, lはプロファイルの幅（ $20 \mu \mathrm{m})$ である. 式の定義より, RMS 值はべー スラインに対して凸部の平均高さを意味する. ただ，本計算では，ベースラインが主粒子表面 ではなく, 被覆粒子層の内部に存在することか ら, 主粒子表面からの被覆高さは RMS 值の約 2 倍に相当すると考えられる。

また，別の定量的粗さ情報として，主要な凹 凸周期を取得するため, 各高さプロファイルに 対して FFT（高速フーリエ変換）処理を行った. フーリエ級数の基礎式を次に示す.

$$
\begin{aligned}
& f(x)=\frac{a_{0}}{2}+\sum_{n=1}^{\infty}\left(a_{n} \cos n x+b_{n} \sin n x\right) \\
& P_{n}=\sqrt{a_{n}{ }^{2}+b_{n}{ }^{2}}
\end{aligned}
$$

通常は周期に対する $P_{n}$ を算出する場合が多

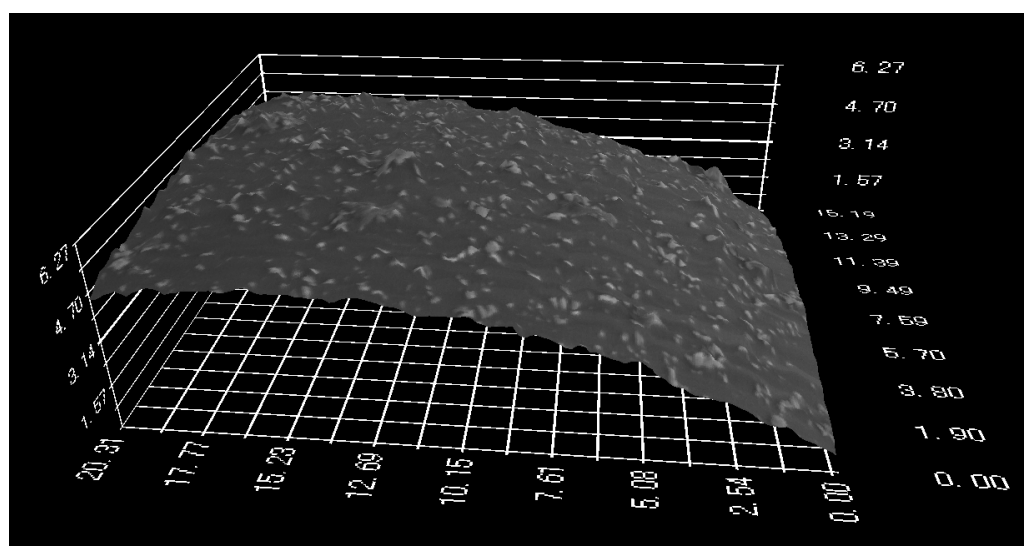

Fig. 2 A example of three-deimensional SEM images $(60.8 \mu \mathrm{m}-8 \mathrm{~nm}, 0.10$ mass $\%$, scale unit: $\mu \mathrm{m})$. 
いが，表面粗さをイメージしやすくするため， 本研究では波長に対する $P_{n}$ を算出した。なお， FFT 処理を行う際には，空関数として Hanning 空を用いた。

\section{研 究成果}

\section{1． 添加割合が流動性向上効果に及ぼす影響}

Fig. 3 に各添加割合 $R_{\mathrm{m}}$ に対する排出流量向上 量 $\Delta Q_{\mathrm{d}}$ を示す．この結果から，全ての主粒子と 添加粒子の組み合わせにおいて上に凸の傾向が 確認できる。 また，各組み合わせにおける $\Delta Q_{\mathrm{d}}$ のピーク時を比較するとそれぞれ $60.8 \mu \mathrm{m}-8 \mathrm{~nm}$ で $15.1 \mathrm{mg} / \mathrm{s} \quad(0.10 \mathrm{mass} \%), 60.8 \mu \mathrm{m}-104 \mathrm{~nm}$ で $12.4 \mathrm{mg} / \mathrm{s} \quad(0.05 \mathrm{mass} \%), 41.4 \mu \mathrm{m}-8 \mathrm{~nm}$ で $19.3 \mathrm{mg} / \mathrm{s}$ （0.05 mass\%）であることがわかる. これより, 同じ主粒子径では添加粒子径が小さ い方が $\Delta Q_{\mathrm{d}}$ の最大值が大きく, 同じ添加粒子 径でも主粒子径が小さい方が $\Delta Q_{\mathrm{d}}$ の最大值が 大きいことが明らかとなった。このうち，前者 の添加粒子径が及ぼす影響については，圧密充 填時の傾向（Yoshida M. et al., 2013）と同じで あるものの，後者の主粒子径が及ぼす影響につ いては, 圧密充填時の傾向 (Yoshida M. et al., 2017）と逆であることが明らかとなった。この 理由の詳細は不明であるが，緒言でも述べたよ

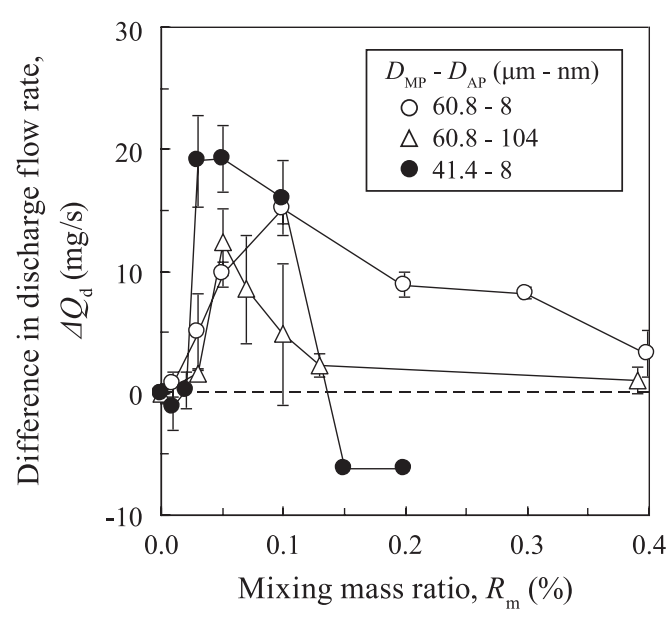

Fig. 3 Differences in discharge flow rate as a function of mixing mass ratios.
うに圧密流動は時間変化に伴い粒子間距離が狭 まる挙動であるのに対して, 本振動排出流動は 粒子間距離が広がる挙動であることにより，粒 子の接触状態が異なることが要因の 1 つである と考えられる。また，本結果より，対象となる 粉体プロセスによって流動性向上メカニズムが 異なる可能性があることが示唆された。

\section{2. 被覆高さが流動性向上効果に及ぼす影響}

Fig. 3 の結果においては $\Delta Q_{\mathrm{d}}$ の絶対值につい て議論をしたが， $\Delta Q_{\mathrm{d}}$ が最大值を示す添加割合 $R_{\mathrm{m}}$ が異なることも示された。具体的には， $60.8 \mu \mathrm{m}-8 \mathrm{~nm}$ と $41.4 \mu \mathrm{m}-8 \mathrm{~nm}$ で比較すると, $60.8 \mu \mathrm{m}$ の方が 2 倍大きい $R_{\mathrm{m}}$ の条件で $\Delta Q_{\mathrm{d}}$ が 最大值を示すことが明らかとなった，ただ，両 者は，主粒子の全表面積が異なるだけでなく， 粒子径の組み合わせによって混合時の接触状態 が異なり，被覆状態が大きく異なった可能性が ある。よって，実際の被覆状態を元に議論する ことが重要であると考えられる。

Fig. 4 に $60.8 \mu \mathrm{m}-8 \mathrm{~nm}$ の条件において $\Delta Q_{\mathrm{d}}$ が最大值を示した $0.10 \mathrm{mass} \%$ の SEM 画像とそ の粗さプロファイル例を示す。結果より, 約土 $0.2 \sim 0.3 \mu \mathrm{m}$ 程度の高さの凹凸が確認でき，凹 凸の周期も数 $\mu \mathrm{m}$ 程度であることがわかる。 Fig. 5 に $R_{\mathrm{m}}$ に対してこれらの高さプロファイ ルより算出した RMS 值 $(60.8 \mu \mathrm{m}-8 \mathrm{~nm}$ の条件 $)$ を示す. 結果より, RMS は $R_{\mathrm{m}}$ の増加に伴い緩 やかに増加することがわかる．Fig. 3 において， 本試料 $(60.8 \mu \mathrm{m}-8 \mathrm{~nm})$ は $R_{\mathrm{m}}=0.10 \mathrm{mass} \%$ に おいて $\Delta Q_{\mathrm{d}}$ が最大值を示したこと考慮すると， $\Delta Q_{\mathrm{d}}$ が最大值を示す RMS は約 $0.1 \mu \mathrm{m}$ であると 言える.

Fig. 6 に全ての粒子径の組み合わせにおける RMS に対する $\Delta Q_{\mathrm{d}}$ の結果を示す。結果より， いずれの試料においても RMS が約 $0.1 \mu \mathrm{m}$ にお いて $\Delta Q_{\mathrm{d}}$ が最大值を示していることが明らか となった。また，「研究方法」の 3 節でも述べ たように，主粒子表面からの被覆高さは RMS 值の 2 倍に相当すると考えられることから，い ずれの試料においても約 $0.2 \mu \mathrm{m}$ の被覆高さを 


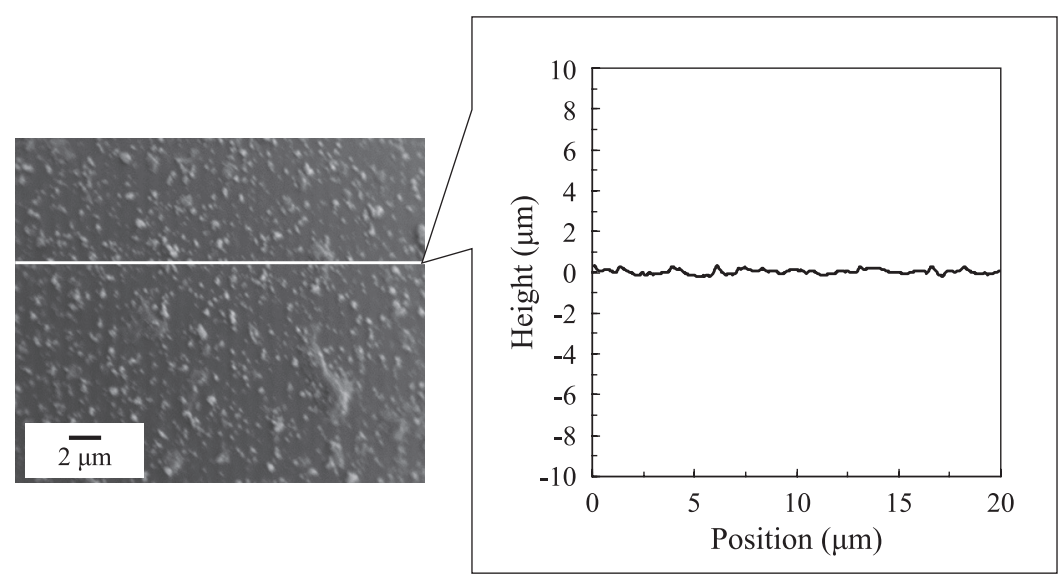

Fig. 4 A surface height profile obtained from a three-dimensional SEM image $(60.8 \mu \mathrm{m}-8 \mathrm{~nm}, 0.10$ mass $\%)$.

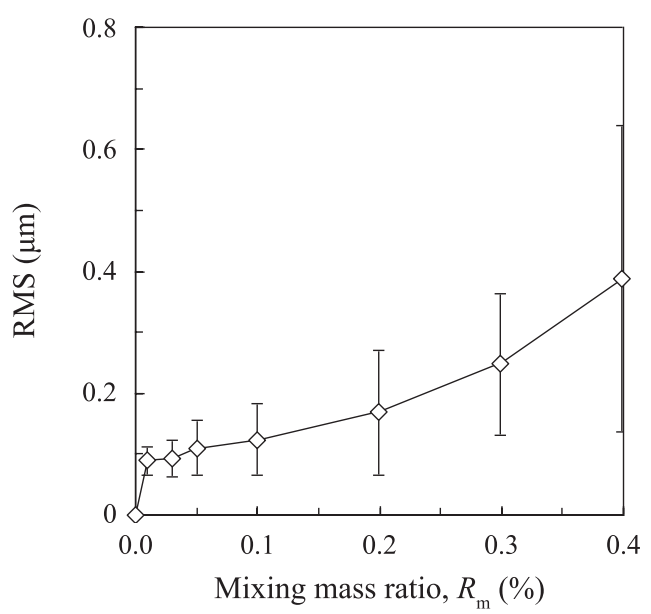

Fig. 5 RMS value as a function of mixing mass ratio $(60.8 \mu \mathrm{m}-8 \mathrm{~nm})$.

持つ場合に $\Delta Q_{\mathrm{d}}$ が最大值を示すと言える.

\section{3．被覆幅が流動性向上効果に及ほすす影響}

Fig. 7 に $60.8 \mu \mathrm{m}-8 \mathrm{~nm}$ の試料における波長に 対する FFT 解析結果を示す。結果より, Fig. 3 において $\Delta Q_{\mathrm{d}}$ 值の比較的大きかった $0.05,0.1$, 0.2 mass\% の場合にのみ波長 $3.2 \mu \mathrm{m}$ でピークが 現れていることが確認できる。 また， $60.8 \mu \mathrm{m}-$ $104 \mathrm{~nm}, 41.4 \mu \mathrm{m}-8 \mathrm{~nm}$ の FFT 解析結果におい ても，それぞれ 0.03 と $0.05 \mathrm{mass} \%, 0.05$ と 0.10 mass\% の条件で波長 $3.2 \mu \mathrm{m}$ でピークが確 認できることが明らかとなった。これらはいず れも $\Delta Q_{\mathrm{d}}$ 值が比較的大きい条件であることか

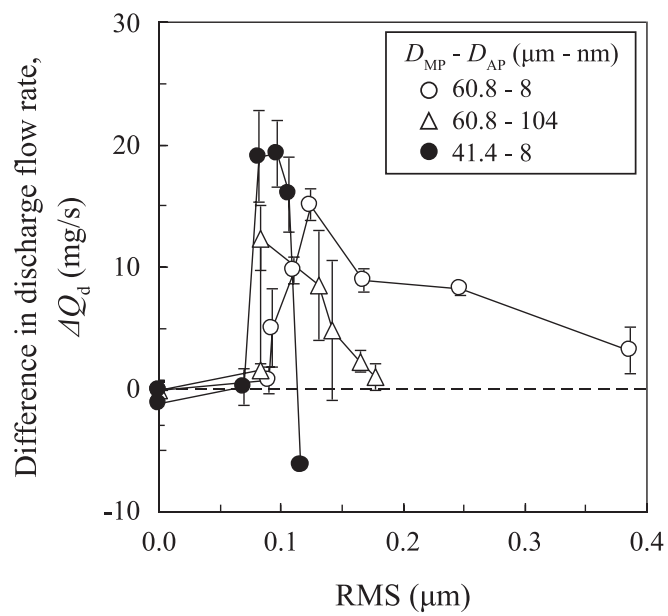

Fig. 6 Difference in discharge flow rate as a function of RMS value.

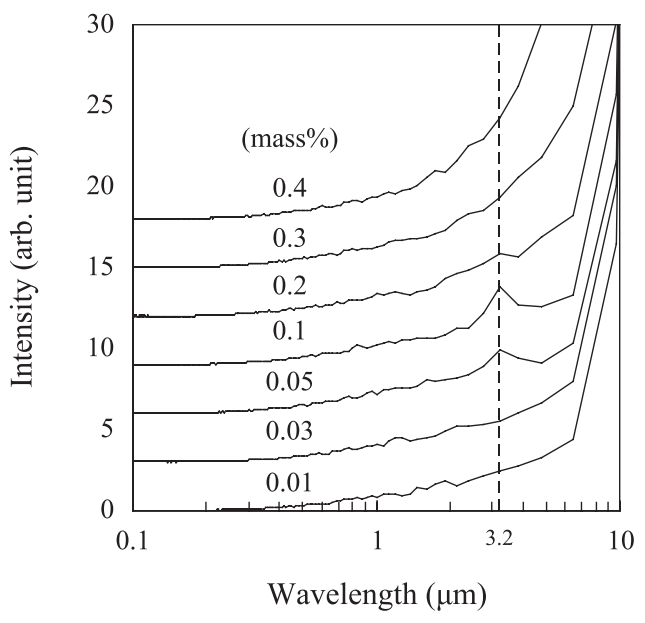

Fig. 7 FFT results $(60.8 \mu \mathrm{m}-8 \mathrm{~nm})$. 
ら，流動性向上効果に大きく寄与をしていると 考えられる。また， $60.8 \mu \mathrm{m}-8 \mathrm{~nm}$ で $\Delta Q_{\mathrm{d}}$ 值が 最大值を示した高さプロファイルを既に Fig. 4 に示したが, 波長 $3.2 \mu \mathrm{m}$ 程度の周期も確認で きることから本結果は実際の凹凸構造を反映し た結果であると考えられる。

\section{参考文献}

Chen Y., Jallo L., Quintanilla M.A.S., Dave R., Characterization of particle and bulk level cohesion reduction of surface modified fine aluminum powders, Colloids and Surfaces A: Physicochemical and Engineering Aspects, 361 (2010) 66-80. DOI: 10.1016/j.colsurfa.2010.03. 015

Jonat S., Hasenzahl S., Drechsler M., Albers P., Wagner K.G., Schmidt P.C., Investigation of compacted hydrophilic and hydrophobic colloidal silicon dioxides as glidants for pharmaceutical excipients, Powder Technology, 141 (2004) 31-43. DOI: 10.1016/j.powtec.2004.01.020

Miwa S., Funtai Kogaku Tsuron, Nikkan Kogyo, (1981) 121149. 三輪 茂雄, 粉体工学通論, 日刊工業新聞社, 1981, pp.121-149. ISBN: 9784526012181.

Yoshida M., Yamamoto H., Oshitani J., Gotoh K., Effects of

\section{口頭・ポスター発表}

1. 金児 尚弥, 下坂 厚子, 吉田 幹生, 白川 善幸, “微小粒子添加による排出流動性向上効果に 及ぼす排出振動数と被覆状態の影響”，粉体 工学会 2017 年度春期研究発表会（Tokyo,

the agglomerated states and the gap of coverage for admixed particles on particle-bed packing fractions, Advanced Powder Technology, 24 (2013) 560-564. DOI: 10.1016/j.apt.2013.01.004

Yoshida M., Sanagawa T., Okano S.-i., Yamamoto H., Oshitani J., Gotoh K., Paul J., Koch T., Peukert W., Effects of an adhesive force of admixed particles on compressed packing fractions in a particle bed, Advanced Powder Technology, 26 (2015) 626-631. DOI: 10.1016/j.apt. 2015.01.014

Yoshida M., Takatsuki R., Sakamoto G., Oshitani J., Gotoh K., DEM simulation and analysis of the effects of adhesive forces and rotations of admixed particles on improving main particle flowability, Advanced Powder Technology, 27 (2016) 2084-2093. DOI: 10.1016/j. apt.2016.07.021

Yoshida M., Misumi A., Oshitani J., Gotoh K., Shimosaka A., Shirakawa Y., Effects of main particle diameter on improving particle flowability for compressed packing fraction in a smaller particle admixing system, Advanced Powder Technology, 28 (2017) 2542-2548. DOI: 10.1016/j.apt.2017.07.004

Zimmermann I., Eber M., Meyer K., Nanomaterials as flow regulators in dry powders, Zeitschrift für Physikalische Chemie, 218 (2004) 51-102. DOI: 10.1524/zpch.218. 1.51 .25388

May. 16-17, 2017)，一般 -18, pp. 96-97.

2. 吉田 幹生, 片山達貴, 押谷潤, 後藤邦彰, 下坂 厚子, 白川 善幸, “微小粒子添加によ る主粒子表面粗さが振動排出時の流動性向 上効果に及ぼす影響”，第 55 回粉体に関す る討論会（Shiogama, Nov. 13-15, 2017），16, pp. 67-71. 